\title{
ANÁLISE DO DESEMPENHO DE ALUNOS INGRESSANTES DE ENGENHARIA NA DISCIPLINA DE CÁLCULO DIFERENCIAL E INTEGRAL I
}

\author{
PERFORMANCE ANALYSIS OF ENGINEERING FIRST-YE \\ AR STUDENTS IN DIFFERENTIAL AND INTEGRAL CALCULUS
}

Edinéia Zarpelon ${ }^{1}$

Luis Mauricio Martins de Resende ${ }^{2}$

Ednei Felix Reis ${ }^{3}$

\section{Resumo}

Este artigo tem como objetivo avaliar variáveis a fim de verificar quais delas são efetivamente significativas para a reprovação de alunos ingressantes de cursos de engenharia na disciplina de Cálculo Diferencial e Integral I. Por meio de uma pesquisa bibliográfica, elencou-se os fatores mais citados como passíveis de influenciar o desempenho de alunos ingressantes de engenharia, identificando-se dois principais eixos temáticos: conhecimento matemático prévio e estrutura didático/pedagógica dos cursos de engenharia. Desses eixos foram associadas e investigadas as seguintes variáveis: nota obtida pelos estudantes na prova de Matemática do Exame Nacional do Ensino Médio (ENEM), pesos atribuídos às provas de Matemática do ENEM, período de ingresso no curso (outono ou primavera), conhecimento matemático básico prévio, carga horária semanal de aulas a que são submetidos esses alunos e metodologia de avaliação diferenciada. Para tal análise utilizou-se de um estudo de caso, tendo como foco a Universidade Tecnológica Federal do

\footnotetext{
${ }^{1}$ A autora é Doutoranda no Programa de Pós-Graduação em Ensino de Ciência e Tecnologia da UTFPR - Câmpus, Ponta Grossa. É Professora do Departamento Acadêmico de Matemática da UTFPR - Câmpus Pato Branco. E-mail: ezarpelon@utfpr.edu.br

$2 \mathrm{O}$ autor é Professor titular da Universidade Tecnológica Federal do Paraná (UTFPR), Câmpus, Ponta Grossa. É Doutor em Engenharia Mecânica pela Universidade Federal de Santa Catarina (2001). E-mail: lmresende@utfpr.edu.br

3 O autor é Professor da Universidade Tecnológica Federal do Paraná (UTFPR), Câmpus, Ponta Grossa, é Doutor em Matemática pela University of Southern California (2011). E-mail: edneif@utfpr.edu.br
} 
Paraná (UTFPR). Trata-se de uma pesquisa quantitativa, cuja amostra é composta por 3.010 ingressantes nos cursos de engenharia em dois câmpus da UTFPR, no período compreendido de 2010 a 2014. Os dados foram coletados por meio de consultas ao sistema acadêmico institucional e aplicação de testes junto aos alunos ingressantes. Em síntese, os resultados apontam para a existência de relação entre o desempenho acadêmico em Cálculo Diferencial e Integral I e as cinco primeiras variáveis supramencionadas. Quanto à metodologia de avaliação diferenciada aplicada neste estudo os resultados não trazem evidências da influência desta variável no desempenho acadêmico.

Palavras-chave: Engenharia. Cálculo Diferencial e Integral I. Reprovação.

\section{Abstract}

This research aims to analyse factors in order to understand their significance to the failure of Engineering freshmen students in Differential and Integral Calculus I. Through a literature search, we identified some of the most cited factors which may influence the performance of freshman engineering students, and we sorted them into two main categories: prior mathematical knowledge and educational structure / teaching of engineering courses. From these themes, we investigated the following variables: the grade achieved by the students in the Mathematics test of the Brazilian High School National Exam (Exame Nacional do Ensino Médio, ENEM); weights assigned to ENEM Mathematics test; term of course admission (fall or spring); previous knowledge on Mathematics; course load; and a distinct evaluation methodology. For this analysis, we used a case study focusing on the Federal Technological University of Paraná (UTFPR). This is a quantitative survey whose sample consists of 3,010 freshmen in engineering courses on two UTFPR campuses, in the period from 2010 to 2014. Data related to the quantitative variables were collected through searches in the institution's academic system and by applying tests to first-year students. In summary, the results indicate the existence of a relationship between academic performance in Differential and Integral Calculus I and the first five variables above. As for the distinct evaluation methodology applied in this study, the results do not provide evidence of the influence of this variable in academic performance.

Key-words: Engineering. Differential and Integral Calculus. Failure. 


\section{INTRODUÇÃO}

A reprovação é um problema educacional presente em todos os níveis de ensino que além de impedir a progressão do aluno indica que houve falhas no processo ensino-aprendizagem. No ensino superior, o elevado número de reprovações em determinadas disciplinas tem sido um obstáculo enfrentado por diversas instituições.

Na Universidade Tecnológica Federal do Paraná (UTFPR) os maiores índices de insucesso estão centrados nas disciplinas da área de exatas - como Cálculo, Física e Geometria Analítica e Álgebra Linear - nos cursos de Engenharia. Estas disciplinas tratam de conteúdos gerais que sustentarão aprendizagens posteriores, em disciplinas específicas.

Em particular, os índices de reprovação em Cálculo Diferencial e Integral $I^{4}$ na UTFPR são elevados, fato que justifica a realização desta pesquisa, especialmente devido à gama de cursos graduação (tecnologias, engenharias e licenciaturas) cuja matriz curricular abarca a disciplina em questão: a mesma está presente em 81 dos 105 cursos ofertados em 13 câmpus da instituição.

Pesquisas têm tratado as reprovações em Cálculo I sob diferentes pontos de vista, buscando identificar e explorar o que realmente tem interferido no desempenho dos alunos. Dentre os trabalhos analisados, alguns (CAVASOTTO, 2010; FERNANDES FILHO, 2001; MENESTRINA; MORAES, 2011; SANTAROSA; MOREIRA, 2011; SOARES DE MELLO; FERNANDES, 2001) mencionam em seu escopo a deficiência na formação matemática básica como um fator relevante para justificar a falta de êxito na disciplina.

\footnotetext{
${ }^{4}$ Também denominada, simplesmente, de Cálculo I.
} 
Num outro viés existem trabalhos, como o de Garzella (2013), sugerindo que o fracasso dos acadêmicos é decorrente da forma rígida e inflexível em que a disciplina de Cálculo I está organizada, bem como das práticas pedagógicas adotadas pelos professores. Corrobora em parte essa concepção, de que o fator determinante para o insucesso acadêmico está no sistema didático em que a disciplina está apoiada, o trabalho de Barbosa (2004).

Evidentemente, os fatores mencionados são relevantes e podem ser potencializados por outras variáveis que colaboram para a perpetuação dos quadros de insucesso. Assim, esse trabalho busca investigar a influência de algumas variáveis associadas a dois eixos temáticos principais: conhecimento prévio de matemática e estrutura didático/pedagógica dos cursos de engenharia.

Para o primeiro eixo temático foram analisadas as seguintes variáveis: nota obtida pelos estudantes na prova de Matemática do Exame Nacional do Ensino Médio (ENEM), pesos atribuídos às provas de Matemática do ENEM, período de ingresso no curso e conhecimento matemático básico. Para o segundo eixo temático as variáveis analisadas foram: carga horária semanal de aulas a que os acadêmicos estão submetidos no primeiro período e metodologia de avaliação diferenciada.

Ressalta-se que estudos desta natureza se justificam visto que a reprovação é apontada como uma das causas para a evasão e esta, por sua vez, gera grande desperdício de recursos financeiros, carência de profissionais capacitados no mercado de trabalho e põe fim ao sonho de muitos estudantes. Assim, a análise e a reflexão sobre os principais fatores que influenciam o 
desempenho de alunos ingressantes nos cursos de engenharia pode contribuir para que professores e gestores institucionais busquem medidas paliativas para combater tal problema.

\section{REPROVAÇÕES EM CÁLCULO I NOS CURSOS DE ENGENHARIA}

O ingresso no ensino superior marca o início de um novo ciclo na vida de qualquer aluno. Em oposição ao ensino médio onde, geralmente, o estudante desempenha um papel mais passivo, no ambiente universitário o estudante "é cobrado a direcionar e programar com mais liberdade, autonomia e responsabilidade o seu aprendizado" (BAZZO; VALE PEREIRA, 2013, p. 23). Este fato já representaria uma mudança significativa, fortalecendo a ideia de que nesta fase ocorre um rompimento e não uma continuidade entre esses dois níveis de ensino.

Todavia, em muitos casos essa mudança extrapola o âmbito acadêmico e engloba outras esferas, visto que muitos alunos precisam mudar de cidade, deixar suas famílias e morar sozinhos ou com pessoas desconhecidas, administrar problemas de ordem financeira e emocional, ou seja, conciliar os horários de estudo com outros afazeres externos ao ambiente universitário.

Para os ingressantes nos cursos de engenharia essa fase é mais tumultuada, pois além destes empecilhos os alunos precisam lidar com uma carga horária semanal de aulas de matemática diluída nas disciplinas de Cálculo I, Física I e Geometria Analítica e Álgebra Linear.

Em particular, a disciplina de Cálculo I é uma das que requer mais esforço, pois possui carga-horária elevada (seis aulas semanais) e os conteúdos abordados nela amparam-se em conteúdos matemáticos básicos, o que pode 
representar um obstáculo para alunos com conhecimentos matemáticos prévios insuficientes.

Lopes (1999) é um dos autores que defende que a falta de conhecimentos matemáticos associados à educação básica é uma das principais razões para justificar o elevado número de reprovações em Cálculo nas universidades brasileiras. A mesma visão é compartilhada por outros pesquisadores. (FERNANDES FILHO, 2001; SOARES DE MELLO; FERNANDES, 2001).

Implicitamente, Lopez e Segadas (2014) também sugerem que o conhecimento matemático prévio é uma das variáveis que interfere neste contexto de excessivas reprovações na disciplina de Cálculo I, haja vista que em um estudo - realizado com 374 ingressantes em engenharia admitidos em 2008 na Escola Politécnica da Universidade Federal do Rio de Janeiro (UFRJ) os pesquisadores correlacionaram os resultados obtidos pelos alunos nas provas do vestibular e na disciplina de Cálculo I.

Na perspectiva discente, a deficiência em relação à matemática básica também está presente. Numa pesquisa realizada por Curi e Farias (2008), os alunos dos cursos de engenharia da Universidade Federal de Campina Grande (UFCG) relataram ter dificuldades em conhecimentos básicos que os conteúdos de Cálculo exigem, fato que dificulta os estudos na disciplina.

Ou seja, a defasagem em relação ao conhecimento matemático básico, demonstrada pela maioria dos ingressantes em cursos de graduação, tem se mostrado um problema recorrente nas universidades, assustando professores, alunos e coordenadores. (MENESTRINA; MORAES, 2011). 
Numa outra perspectiva, a metodologia de ensino e a didática adotada pelos professores são apontadas por alguns autores como causas para os elevados índices de reprovação. Um deles é Barbosa (2004), que num estudo procurou determinar se o grau de abstração exigido na disciplina de Cálculo I e se as ideias complexas trabalhadas em ritmo acelerado não estariam dificultando a aprendizagem dos alunos. Dentre as conclusões obtidas, o pesquisador afirma que "o sistema didático na qual a disciplina está ancorada é um fator determinante para o insucesso do aluno na disciplina" (p.84).

Outra pesquisa que corrobora com esta concepção foi realizada por Garzella (2013). A pesquisadora analisou as repercussões das práticas pedagógicas adotadas por docentes no processo de ensino-aprendizagem e na vida acadêmica e pessoal dos alunos. Amparada nos resultados de seu estudo, concluiu que as formas de estruturação e organização da disciplina - planejada e desenvolvida de forma rígida e inflexível - são fortes componentes que dificultam a aprendizagem dos alunos ingressantes. Além disso, argumenta que a qualidade da mediação desenvolvida pelo professor em sala de aula também é um fator relevante e que contribui para o aproveitamento insatisfatório de boa parte dos alunos. Para a pesquisadora, dentre todos fatores inseridos neste contexto (ruptura entre a matemática trabalhada no ensino médio e a matemática do ensino superior, número excessivo de alunos por turma, quantidade exagerada de conteúdos previstas para o semestre), a prática pedagógica é um dos principais determinantes do sucesso ou fracasso da disciplina, uma vez que as posturas e práticas adotadas pelos professores podem auxiliar ou dificultar o processo de apropriação do conhecimento, logo terão impactos na aprendizagem. 
O fato é que "historicamente o Cálculo serviu como um filtro em muitas escolas de engenharia" (HENSEL et al., 2008, p. 01, tradução nossa) e a dificuldade do aluno em obter sucesso neste componente curricular é um dos principais motivos para que os mesmos deixem o curso no primeiro ano. $\mathrm{Ou}$ seja, a reprovação nesta disciplina passa a ser um dos fatores que contribui para a evasão nos cursos, conforme também indica o trabalho de Bogaard (2012).

Cientes, preocupadas e tentando minimizar este problema, as instituições têm investido em iniciativas diversificadas. As ações englobam desde a oferta de horários de atendimento extraclasse com os docentes, cursos de nivelamento e monitorias, alterações na estrutura curricular dos cursos, modificações na carga horária da disciplina, até mudanças na forma de acesso ao ensino superior, conforme relatam Soares de Mello e Fernandes (2001) e Santarosa e Moreira (2011).

Parte das ações supramencionadas também foram adotadas pela UTFPR, porém a quantidade de alunos reprovados a cada semestre mantem-se elevada. Diante disso, buscou-se verificar se existem indicativos de que o desempenho dos alunos ingressantes na disciplina de Cálculo I é influenciado pelas seguintes variáveis: nota obtida na prova de Matemática do ENEM, pesos diferenciados para as provas de Matemática do ENEM, período de ingresso no curso, conhecimento matemático básico, carga horária total de aulas no primeiro período do curso e metodologia de avaliação diferenciada (aplicação de testes de conhecimento semanais). 


\section{ASPECTOS METODOLÓGICOS}

Este estudo teve como base para seu desenvolvimento uma pesquisa aplicada. Por representar uma situação real que ocorre na UTFPR - instituição na qual os pesquisadores atuam - essa foi escolhida como estudo de caso, ainda porque existe grande interesse no sentido de contribuir na busca de alternativas para combater o problema das reprovações em Cálculo I.

Quanto aos objetivos, esta pesquisa é de cunho explicativo, pois busca identificar os fatores que determinam ou contribuem para a ocorrência do fenômeno. Para Gil (2002, p. 42), “[...] esse é o tipo de pesquisa que mais aprofunda o conhecimento da realidade, porque explica a razão, o porquê das coisas". Essa busca permitiu que ocorresse uma maior familiaridade com o problema, tornando-o mais explícito no sentido de apurar as principais variáveis inseridas no contexto em questão.

Do ponto de vista da forma de abordagem do problema a pesquisa caracteriza-se como quantitativa, pois o problema requerer a identificação de variáveis que influenciam um resultado específico (CRESWELL, 2010), neste caso que influenciem na reprovação em Cálculo I. Neste sentido, Santarosa e Moreira (2011) reforçam a importância de medições e análises estatísticas em discussões de fenômenos como a evasão e a reprovação.

Quanto à delimitação do universo, a população deste estudo é composta pelos alunos ingressantes nos cursos de Engenharia da UTFPR. Para esse trabalho foi utilizado como amostra alunos que ingressaram em dois dos 13 câmpi que a universidade possui: Pato Branco (PB) e Ponta Grossa (PG), nos seguintes cursos: Engenharia Civil, Engenharia da Computação, Engenharia Elétrica e Engenharia Mecânica, da UTFPR (Câmpus PB), e 
Engenharia Eletrônica, Engenharia Mecânica, Engenharia de Produção e Engenharia Química (Câmpus PG). Os dados analisados foram daqueles alunos que ingressaram na instituição em um dos períodos compreendidos entre primeiro semestre de 2010 e o segundo semestre de 2014, inclusive.

Convém esclarecer que desde 2010 a UTFPR utiliza unicamente a nota do ENEM como critério de seleção para ingresso nos cursos ofertados pela instituição, fato que justifica a eleição deste ano como ponto de partida para a coleta de dados. Assim, para a abordagem de quatro, das seis variáveis analisadas, foram obtidos dados de 3.010 acadêmicos ingressantes, sendo 1.492 do Câmpus Pato Branco e 1.518 do Câmpus Ponta Grossa. Quanto as outras duas variáveis, as amostras foram diferenciadas.

Em relação ao conhecimento matemático básico, foi utilizada uma amostra de 419 alunos ingressantes, sendo 269 deles do Câmpus Pato Branco e 150 do Câmpus Ponta Grossa.

Quanto à metodologia de avaliação diferenciada, foi utilizada uma amostragem de 312 alunos, referente a 10 turmas ofertadas de 2012 a 2014, todas no Câmpus Ponta Grossa. Neste caso, 161 alunos (distribuídos em 5 turmas) não participaram da metodologia de testes semanais e 151 acadêmicos (pertencentes a outras 5 turmas) participaram.

A coleta de dados para cada uma das variáveis envolveu a utilização de instrumentos distintos, sendo os mesmos apresentados no quadro 1. 
Quadro 1 - Ferramentas utilizadas na coleta de dados

\begin{tabular}{|l|l|}
\hline \multicolumn{1}{|c|}{ Variáveis de Estudo } & \multicolumn{1}{|c|}{ Ferramentas para Coleta de Dados } \\
\hline 1. Nota obtida na prova de Matemática do ENEM & $\begin{array}{l}\text { Consulta ao Sistema Acadêmico } \\
\text { Institucional }\end{array}$ \\
\hline $\begin{array}{l}\text { 2. Pesos adotados para as provas de Matemática } \\
\text { do ENEM }\end{array}$ & $\begin{array}{l}\text { Consultas aos Editais de Processos } \\
\text { Seletivos }\end{array}$ \\
\hline 3. Período de ingresso no curso & $\begin{array}{l}\text { Consulta ao Sistema Acadêmico } \\
\text { Institucional }\end{array}$ \\
\hline 4. Conhecimento matemático básico & Aplicação de um Teste Diagnóstico \\
\hline 5. Carga horária semanal de aulas & $\begin{array}{l}\text { Consultas aos Projetos Pedagógicos de } \\
\text { Curso }\end{array}$ \\
\hline 6. Metodologia de avaliação diferenciada & $\begin{array}{l}\text { Aplicação de Testes Semanais de } \\
\text { Conhecimento }\end{array}$ \\
\hline
\end{tabular}

Fonte: Zarpelon (2016).

O Teste Diagnóstico foi aplicado nas turmas de alunos ingressantes dos oito cursos de Engenharia estudados, no segundo semestre de 2013 e nas entradas de outono e primavera de 2014. Este teste era composto por 15 itens de caráter dissertativo englobando conteúdos matemáticos de nível fundamental e médio (considerados pré-requisitos) e foi elaborado por um professor da disciplina de Cálculo I da instituição. O teste foi resolvido pelos alunos até a segunda semana de aula. Após a correção, tabulou-se o número de acertos de cada um dos alunos que realizou esta avaliação.

Quanto ao uso de uma metodologia de avaliação diferenciada, essa consistiu em aplicar-se testes semanais ao longo da disciplina de Cálculo I. Cada teste era composto por duas questões discursivas, envolvendo os conteúdos ministrados na semana anterior e aplicados ao final da última aula da semana corrente, sendo vedada a consulta ao material. O tempo de duração de cada um destes testes era de aproximadamente vinte minutos. Os testes foram aplicados em duas turmas de Engenharia Eletrônica e três de 
Engenharia de Produção, todas do Câmpus Ponta Grossa. Ressalta-se que na amostra foram computados apenas acadêmicos que ao final da disciplina tiveram frequência igual ou superior a 75\%, excluindo-se aí os desistentes, uma vez que os testes foram aplicados até as últimas semanas letivas.

Além disso, por meio de consultas os Sistema Acadêmico Institucional foi coletada a nota final de cada aluno na disciplina de Cálculo I.

\section{METOdologia de ANÁlise dos DADOS}

A análise dos dados foi realizada por meio do teste sobre duas proporções e do teste qui-quadrado para independência, ou seja, dois testes de hipótese, definido por Triola (2014, p. 316) como “[...] um procedimento para se testar uma afirmativa sobre uma propriedade da população" partindo sempre do pressuposto que a ocorrência de determinado evento seja verdadeira para um nível de significância previamente definido. Neste estudo adotou-se o nível de significância ( ) de 5\% e utilizou-se esses testes nos casos em que os pré-requisitos foram satisfeitos.

O teste sobre duas proporções testa a hipótese nula $\left(H_{0}\right)$ de que a proporção populacional relativa à primeira população $\left(p_{1}\right)$ é igual a proporção populacional relativa à segunda população $\left(\mathrm{p}_{2}\right)$. Simbolicamente, temos: $H_{0}: p_{1}=p_{2}$.

As conclusões deste estudo foram obtidas por meio de softwares estatísticos, sendo que as mesmas amparam-se nas seguintes premissas:

- Se valor $\mathrm{P}$, rejeita-se $\mathrm{H}_{0}$.

- Se valor $\mathrm{P}>$, não se rejeita $\mathrm{H}_{0}$. 
Ressalta-se que o valor P é uma probabilidade associada ao resultado de determinado teste de hipótese e "representa o grau de raridade daquele resultado, considerando-se que a hipótese nula seja verdadeira". (WITTE; WITTE, 2005, p. 284).

Assim, as seis variáveis propostas neste trabalho foram avaliadas da seguinte maneira:

1. Para a variável "nota na prova de Matemática do ENEM" verificouse se alunos ingressantes com melhores desempenhos na prova de Matemática do ENEM tiveram melhores desempenhos na disciplina de Cálculo I. Como a nota mínima para a aprovação em qualquer disciplina na UTFPR é 6,0 escolheu-se a nota 600 como parâmetro para a separação da amostra. Assim, testou-se a afirmação de que a proporção de aprovados em Cálculo I cujo desempenho na prova de Matemática do ENEM foi insatisfatório (menor que 600) é menor do que a proporção de aprovados cujo desempenho na prova de Matemática do ENEM é considerado satisfatório (igual ou superior a 600).

2. Em relação à segunda variável, a investigação foi orientada no sentido de confirmar se o fato da UTFPR ter adotado peso maior ${ }^{5}$ para a prova de Matemática do ENEM possibilitou a seleção de alunos com maior aptidão matemática o que poderia acarretar uma melhora nos índices de aprovação em Cálculo I. Assim, a amostra foi subdividida em: ingressantes no período anterior à adoção de pesos diferenciados para as provas do ENEM e ingressantes após a adoção de pesos diferenciados. Neste caso testou-se a

\footnotetext{
${ }^{5}$ A partir do segundo semestre de 2013 a prova de Matemática do ENEM, para candidatos que almejassem ingressar nos cursos de engenharia da UTFPR, passou a ter peso 4 . De 2010 a 2013-1 a prova de Matemática do ENEM, com vistas ao ingresso nos cursos de engenharia da UTFPR, possuía o mesmo peso que as provas das demais áreas do conhecimento.
} 
afirmativa de que a proporção de aprovados em Cálculo I no período anterior à adoção de pesos diferenciados para as provas do ENEM é menor que a proporção de aprovados após a adoção de pesos diferenciados.

3. Quanto à variável "período de ingresso no curso" a amostra foi separada em ingressantes no primeiro semestre letivo e ingressantes no segundo semestre letivo e a afirmativa testada foi de que a taxa de aprovação em Cálculo I para ingressantes no primeiro semestre letivo é superior à taxa de aprovação para ingressantes no segundo semestre letivo.

4. Em relação à variável "carga horária semanal de aulas" a amostra foi reagrupada em "alunos com carga horária inferior", o que equivale em média 27 aulas semanais, e "alunos com carga horária superior" que corresponde a 31 aulas semanais, em média. Neste caso, a afirmativa testada foi de que a taxa de aprovação em Cálculo I para alunos com menos aulas semanais é superior à taxa de aprovação para alunos com mais aulas semanais.

5. Quanto à "metodologia de avaliação diferenciada" a amostra foi separada em turmas que realizaram os testes semanais de conhecimento e turmas avaliadas por meio de outras ferramentas. A afirmativa testada é que a taxa de aprovação para alunos que não realizaram testes semanais de conhecimento na disciplina de Cálculo I é menor que a taxa de aprovação para alunos que realizaram os testes semanais.

6. As inferências sobre a variável "conhecimento matemático básico" não puderam ser realizadas pelo teste sobre duas proporções porque um dos pré-requisitos para a utilização deste teste não era satisfeita para os dados coletados. Assim, utilizou-se para esta variável apenas o teste qui-quadrado $\left(\chi^{2}\right)$ para a independência. Este teste é utilizado para ajudar a decidir se as 
duas variáveis consideradas na análise são ou não independentes. Em resumo, essa ferramenta testa a afirmativa de que não há associação entre as variáveis.

As conclusões do teste de independência $\left(\chi^{2}\right)$, para o nível de confiança de $95 \%$, baseiam-se nas seguintes premissas:

- Se $\chi^{2} \geq 3,841$ rejeita-se a independência entre as variáveis.

- Se $\chi^{2}<3,841$ não rejeita-se a independência entre as variáveis.

Convém mencionar que o teste $\chi^{2}$ também foi utilizado para a análise das demais variáveis.

\section{APRESENTAÇÃO E DISCUSSÃO DOS RESULTADOS}

Nesta seção serão apresentados os principais resultados obtidos, visando confirmar ou refutar a hipótese de que o desempenho na disciplina de Cálculo I, dos alunos ingressantes nos cursos de Engenharia, é influenciado por cada uma das variáveis investigadas.

\section{a) Nota de matemática do ENEM}

Tabela 1 - Desempenho dos alunos ingressantes de Engenharia da UTFPR em Cálculo I segundo a nota da prova de Matemática do ENEM

\begin{tabular}{l|cccc}
\hline \multicolumn{5}{c}{ Desempenho na prova de Matemática do ENEM } \\
\hline & Aprovados & Reprovados & Matriculados & Valor P \\
Nota $<\mathbf{6 0 0}$ & 29 & 314 & 343 & 0 \\
Nota $\quad 600$ & 952 & 1.715 & 2.667 & 0 \\
\hline
\end{tabular}

Fonte: Adaptado de Zarpelon (2016)

Em relação a primeira variável os dados amostrais, apresentados na tabela 1, apoiam a afirmativa de que a proporção de aprovados em Cálculo I cujo desempenho na prova de Matemática do ENEM foi insatisfatório é menor 
que a proporção de aprovados cujo desempenho na prova de Matemática do ENEM foi considerado satisfatório (visto que o valor $\mathrm{P}=0<0,05$, levando a rejeição da igualdade entre as proporções).

Esta conclusão se aproxima do resultado obtido por Lopez e Segadas (2014), de que o desempenho em Cálculo I está relacionado ao desempenho no vestibular, especialmente com a nota obtida nas provas específicas (matemática, física e química).

Entretanto, ressalta-se que apesar da existência de inúmeros trabalhos que tratam das possíveis causas para as reprovações em Cálculo "poucos são os que fazem conexões entre o desempenho que o aluno obteve para entrar na universidade com aquele que tem no curso de Cálculo I " (LOPEZ; SEGADAS, 2014, p. 94). Este fato evidencia uma lacuna a respeito do tema e aponta para a necessidade de que outros estudos envolvam análises semelhantes a estas, a fim de corroborar (ou não) as conclusões obtidas.

De todo modo, uma análise inicial acerca da relação entre a nota na prova de Matemática obtida o ENEM e o desempenho em Cálculo I permite inferir que a expansão dos cursos de engenharia, através da ampliação do número de vagas e criação de novos cursos em todo país, tenha contribuído para a seleção de alunos "menos preparados". Essa preocupação já fora mencionada por Fernandes Filho (2001) no início dos anos 2000. Amparado pelos resultados de algumas pesquisas realizadas com ingressantes em cursos de engenharia no final da década de 90, o autor sinalizava que a expansão quantitativa de cursos de engenharia "alterou a relação do número de candidatos por vagas no vestibular, ocasionando a admissão de alunos menos 
preparados, e acarretou a queda no nível de desempenho nas disciplinas da área da matemática". (FERNANDES FILHO, 2001, p. 17).

\section{b) Uso de pesos nas notas do ENEM}

Tabela 2 - Desempenho dos alunos ingressantes de Engenharia da UTFPR em Cálculo I segundo a forma de ingresso

\begin{tabular}{l|cccc}
\hline \multicolumn{5}{c}{ Forma de Ingresso } \\
\hline & Aprovados & Reprovados & Matriculados & Valor P \\
ENEM Sem peso & 684 & 1.493 & 2.177 & 0,0182 \\
ENEM Com peso & 295 & 538 & 833 & \\
\hline
\end{tabular}

Fonte: Adaptado de Zarpelon (2016).

Para a segunda variável, cujos dados amostrais são apresentados na tabela 2, o teste sobre duas proporções sugere que após a adoção de pesos diferenciados para as provas do ENEM a taxa de aprovação na disciplina de Cálculo I aumentou, uma vez que a igualdade entre as proporções amostrais é rejeitada (valor $\mathrm{P}=0,0182<0,05$ ).

A adoção de pesos diferenciados para as provas que compõem o ENEM foi uma medida adotada pela UTFPR após inúmeras discussões internas junto aos coordenadores de curso, com vistas a melhorar o processo de seleção dos alunos. Partiu-se da premissa de que os melhores candidatos aos cursos de engenharia seriam aqueles que apresentassem maior aptidão pela área de exatas, sendo essa aptidão quantificada por meio das notas obtidas nas provas de Matemática, Física e Química do ENEM, hipótese que justificou a adoção de pesos maiores para as provas dessas áreas do conhecimento. De fato, os resultados obtidos no teste indicam que essa medida paliativa teve algum efeito positivo. 
Esta premissa de que os estudantes que quisessem cursar engenharia deveriam ter melhor conhecimento nas disciplinas de exatas também norteou os processos de seleção - no caso, vestibular por área de conhecimento - da Universidade Federal Fluminense (UFF) antes da década de 70. Porém de 1972 a 1987 a seleção de alunos passou a se dar por meio do vestibular unificado, o que segundo Soares de Mello e Fernandes (2001), contribuiu para o aumento dos índices de insucesso na disciplina de Cálculo visto que os candidatos a cursos de engenharia obrigaram-se a serem "especialistas em generalidades" (2001, p. 09) e passaram a chegar nos cursos sem todos os conhecimentos matemáticos com que chegavam antes da adoção de tal medida.

Em suma, o trabalho de Soares de Mello e Fernandes (2001) apenas reforça os resultados obtidos para as duas primeiras variáveis deste estudo, de que os acadêmicos que apresentam melhor desempenho em Matemática nos processos de seleção tendem a ter um melhor desempenho em Cálculo I.

\section{c) Semestre de entrada no curso}

Tabela 3 - Desempenho dos alunos ingressantes de Engenharia da UTFPR em Cálculo I segundo o período de ingresso

\begin{tabular}{l|cccc}
\hline \multicolumn{5}{c}{ Período de Ingresso no Curso } \\
\hline & Aprovados & Reprovados & Matriculados & Valor P \\
Primeiro Semestre & 587 & 890 & 1.477 & 0 \\
Segundo Semestre & 392 & 1.141 & 1.533 & 0 \\
\hline
\end{tabular}

Fonte: Adaptado de Zarpelon (2016).

Quanto ao período de ingresso no curso (dados na tabela 3) o teste também aponta que os ingressantes no primeiro semestre letivo apresentam desempenho melhor na disciplina. 
Esta conclusão equipara-se à obtida por Lopes (1999), cujo estudo revelou que os percentuais de reprovação em Cálculo I para ingressantes nos cursos de engenharia da Universidade de São Paulo (USP) no primeiro e no segundo semestres de 1996 foram, respectivamente 35\% e 67\%. A justificativa para essa diferença amparava-se exatamente no fato de que os ingressantes no primeiro semestre eram alunos que estavam nas primeiras classificações do vestibular, sugerindo que esse contingente era formado pelos alunos com maior aptidão matemática.

Convém esclarecer que o ingresso na UTFPR ocorre unicamente por meio do ENEM e a nota desse exame é utilizada em dois momentos: para a seleção de alunos ingressantes no primeiro semestre e para a seleção de ingressantes no segundo semestre. Além disso, o peso na prova de matemática (peso 4) interfere de forma expressiva no desempenho final do candidato. Assim, os alunos com as maiores notas no ENEM ingressam no primeiro semestre letivo ao passo que os com notas inferiores ingressam no segundo corroborando as conclusões obtidas nas análises das variáveis anteriores.

Outro agravante é que alunos ingressantes nas últimas chamadas acabam por estar ausentes nas primeiras semanas de aula, levando o aluno a perder o conteúdo inicial de todas as disciplinas e o obrigando-o a retomar esses conteúdos por conta própria, o que demanda um maior comprometimento e empenho, justamente por parte daqueles que, supõe-se, terem maiores dificuldades em relação a área de exatas (devido ao desempenho obtido no ENEM).

Além disso, os resultados obtidos para esta variável também podem ser justificados pela falta de ritmo de estudo dos alunos ingressantes do 
segundo semestre uma vez que estes estudantes não iniciaram no ensino superior logo após a conclusão do ensino médio.

\section{d) Conhecimento matemático básico}

Em relação ao conhecimento matemático básico, o teste diagnóstico aplicado a 419 ingressantes revelou que uma sólida formação matemática contribui para o bom desempenho do aluno na disciplina, visto que $94 \%$ dos alunos que tiveram nove ou mais acertos no teste foram aprovados em Cálculo I, conforme pode-se verificar por meio do quadro 2.

Quadro 2 - Dados do teste diagnóstico

\begin{tabular}{|c|c|c|c|}
\hline $\begin{array}{c}\text { Teste } \\
\text { Diagnóstico }\end{array}$ & $\begin{array}{c}\text { Aprovados em } \\
\text { Cálculo I }\end{array}$ & $\begin{array}{c}\text { Reprovados em } \\
\text { Cálculo I }\end{array}$ & $\begin{array}{c}\text { Total de } \\
\text { alunos }\end{array}$ \\
\hline 12 a 15 acertos & 05 & 00 & 05 \\
\hline 9 a 11 acertos & 11 & 01 & 12 \\
\hline 6 a 8 acertos & 39 & 13 & 52 \\
\hline 3 a 5 acertos & 60 & 23 & 83 \\
\hline 0 a 2 acertos & 89 & 178 & 267 \\
\hline Total & $\mathbf{2 0 4}$ & $\mathbf{2 1 5}$ & $\mathbf{4 1 9}$ \\
\hline
\end{tabular}

Fonte: Autoria própria.

Os dados também mostram que o número de aprovações ainda permanece maior do que o número de reprovações quando considera-se os estudantes que tiveram de 3 a 9 acertos no teste diagnóstico. Além disso, é possível verificar que aproximadamente $82 \%$ dos alunos reprovados, ou seja 178 alunos, não tiveram mais que dois acertos no teste diagnóstico, confirmando que "em muitos casos, os estudantes universitários não sabem os conceitos matemáticos anteriores que são necessários para fazer os cursos de Cálculo." (LOPES, 1999, p. 125). 
Deste modo, há indicativos que alunos com melhor conhecimento prévio de Matemática tendem a ter um melhor resultado na disciplina de Cálculo I.

Alunos que obtiveram menos de três acertos no teste diagnóstico são aqueles que representam o grande contingente de reprovação na disciplina. Caso essas categorias fossem excluídas da amostra, o índice de reprovação cairia de $51 \%$ para $24 \%$. Assim, parece que um pequeno conhecimento inicial é suficiente para boa parte dos alunos obterem sucesso na disciplina de Cálculo I.

Ressalta-se que outros estudos também abordam a importância de verificar o conhecimento prévio a partir de testes diagnósticos, similares ao aplicado na UTFPR. Para Garzella (2013) é importante a realização de uma avaliação diagnóstica no início do curso, de forma que os dados obtidos nesta avaliação possam orientar os professores na decisão sobre onde iniciar a disciplina, uma vez que parte das conclusões obtidas pela pesquisadora revelou que professores e alunos identificaram as lacunas de aprendizagem na transição do ensino médio para o superior como um fator que dificulta o desempenho dos alunos já no início da disciplina.

Uma avaliação diagnóstica também foi realizada por Cavasotto (2010) com o objetivo de verificar o nível de conhecimento matemático de 94 ingressantes em engenharia. A análise de 1692 questões revelou que 893 foram resolvidas incorretamente, sendo que $52 \%$ continham erros associados a conteúdos de ensino fundamental, $40 \%$ a conteúdos de ensino médio e $8 \%$ erros de interpretação. Este estudo não traz dados a respeito dos quantitativos de aprovações ou reprovações na disciplina, mas reforça a necessidade de que 
os conteúdos básicos sejam retomados, de alguma forma, no início da carreira acadêmica.

Na Faculdade de Engenharia da West Virginia University (WVU) o ingresso do aluno na disciplina de Cálculo I está condicionado a um bom desempenho no SAT6-Matemática e mesmo assim os alunos selecionados realizam um teste durante a segunda semana de aula. A partir dos resultados obtidos neste teste os acadêmicos são alertados se estão realmente preparados para permanecer na turma regular de Cálculo I. Caso as notas sejam insatisfatórias, os alunos optam em cursar Pré-Cálculo, fazer um curso de Cálculo I com duração de dois semestres (no qual o conteúdos considerados pré-requisitos podem ser revisados) ou permanecer no curso de Cálculo I, cientes de que terão que se dedicar muito para ter sucesso na disciplina uma vez que a base matemática que possuem não é considerada adequada.

Segundo Hensel et al. (2008, tradução nossa) muitos alunos com baixo desempenho no teste inicial acreditam que o mesmo não reflita sua preparação e conhecimento real e optam em permanecer no curso de Cálculo I. Todavia, muitas vezes os conceitos-chave necessários ao Cálculo estão ausentes e o aluno só percebe isso várias semanas após o início do curso, depois de ter obtido desempenho insatisfatório em duas ou mais avaliações. Neste caso, outras intervenções são realizadas para que esses alunos não abandonem a disciplina e tenham sucesso em Cálculo I.

Em resumo, as pesquisas citadas anteriormente indicam que a deficiência em relação aos conteúdos matemáticos básicos influenciam no

\footnotetext{
${ }^{6}$ O SAT (Scholastic Aptitude Test) é um exame aplicado em nível nacional nos Estados Unidos e é utilizado por universidades americanas nos processos de admissão de alunos para a graduação.
} 
desempenho dos alunos em Cálculo I. Entretanto, conforme percebe-se pelos dados do quadro 2, muitos acadêmicos da UTFPR obtiveram a aprovação na disciplina mesmo sem terem apresentado um desempenho excepcional no teste diagnóstico.

Dentre outras possibilidades (empenho e comprometimento acadêmico), acredita-se que as medidas adotadas pela UTFPR (como oferta de diversos horários de monitoria para a disciplina de Cálculo I e acesso à horários de atendimento específicos com os docentes da disciplina) têm auxiliado os acadêmicos a sanar lacunas de aprendizagem, relativas aos conhecimentos prévios.

\section{e) Carga horária semanal de aula}

Tabela 4 - Desempenho dos alunos ingressantes de Engenharia da UTFPR em Cálculo I segundo a carga horária

\begin{tabular}{l|cccc}
\hline \multicolumn{5}{c}{ Carga horária no primeiro período } \\
\hline & Aprovados & Reprovados & Matriculados & Valor P \\
Inferior & 558 & 937 & 1.495 & 0 \\
Superior & 421 & 1.094 & 1.515 & 0 \\
\hline
\end{tabular}

Fonte: Adaptado de Zarpelon (2016)

Em relação à carga horária a conclusão obtida é que a proporção de aprovados em Cálculo I é maior quando considera-se alunos submetidos a menores cargas horárias, conforme verifica-se pelo valor $\mathrm{P} \quad(<0,05)$ apresentado na tabela 4 .

Uma possível explicação para isso pode estar associada ao fato de que alunos com menores cargas horárias conseguem se dedicar mais a disciplina fora da sala de aula. 
A importância de que sejam dedicados horários para estudos extraclasse visando a retomada dos conteúdos vistos em sala é mencionada por Bazzo e Vale Pereira (2013). Segundo os pesquisadores, "duas horas de estudos extraclasse para cada hora de aula seja uma boa dose para que a recomposição e a fixação dos assuntos sejam alcançadas" (p. 46), entretanto esta recomendação serve como orientação, haja vista que alguns alunos poderão dedicar mais tempo para algumas disciplinas e menos para outras, ou seja, a quantidade de tempo necessária varia de estudante para estudante e depende da capacidade, disposição e estratégias de estudo, sendo que ter mais tempo disponível não acarreta necessariamente no sucesso do aluno. (BOGAARD, 2012, tradução nossa).

Assim, segundo a sugestão proposta por Bazzo e Vale Pereira (2013), os alunos ingressantes de engenharia submetidos a 27 aulas semanais deveriam dedicar 45 horas para estudar fora de sala de aula, sendo que 10 destas horas deveriam ser destinadas à disciplina de Cálculo I. Já os alunos com média de 32 horas aulas deveriam ter disponíveis durante a semana 53 horas para estudos extraclasse, sendo 12 delas para a disciplina de Cálculo I. Esta meta é praticamente inatingível visto que alunos com 27 aulas semanais deverão dispor de aproximadamente 9,5 horas diárias de estudo e os alunos com 32 aulas semanais deverão estudar cerca de 11 horas diárias, todos os dias da semana.

Acredita-se que a elevada carga horária de aulas que os alunos ingressantes de engenharia da UTFPR possuem impossibilita uma maior dedicação fora dos horários de aula e contribui para os quadros de insucesso frente a disciplina de Cálculo I. 
Em Curi e Farias (2008) os professores de Cálculo I entrevistados apontaram a carga horária dos alunos (em geral muito alta) e, consequentemente, o pouco tempo dedicado aos estudos como possíveis causas para o desempenho médio das turmas.

Uma carga horária menor permitiria pensar em medidas paliativas diferenciadas para este problema, como ocorreu na WVU. Nessa instituição a carga típica de alunos ingressantes de Engenharia está entre 15 e 18 horas-aula (HENSEL et al., 2008, tradução nossa), fato que possibilitou a implementação de intervenções - como a criação dos Laboratórios de Estudo e do Centro de Aprendizagem Matemática, bem como o acompanhamento dos acadêmicos nesses ambientes - pela instituição a fim de auxiliar alunos com dificuldades em Cálculo.

Por outro lado, uma das iniciativas não exitosas adotada pela UFF para minimizar as reprovações em Cálculo I foi justamente o aumento da carga horária da disciplina, de 4 para 6 horas semanais. O propósito de tal medida era trabalhar os conceitos elementares que deveriam ter sido vistos no ensino básico no decorrer da disciplina de Cálculo I. Porém, "contrariamente às expectativas, os índices de reprovação subiram bastante, tornando-se alarmantes." (SOARES DE MELLO; FERNANDES, 2001, p. 09).

Assim, diante da impossibilidade de redução da carga horária no primeiro período, é primordial que o tempo disponível extraclasse seja administrado com qualidade e que o aluno consiga fixar metas, desenvolver a capacidade de concentração e procurar ajuda sempre que necessário, ou seja, é necessário que o aluno aprenda a estudar, algo que para Bazzo e Vale Pereira (2013) não é inato e, portanto, precisa ser aprendido. 


\section{f) Metodologia de avaliação diferenciada}

Tabela 5 - Desempenho dos alunos ingressantes em Cálculo I segundo a metodologia de avaliação adotada

\begin{tabular}{l|cccc}
\hline \multicolumn{5}{|c|}{ Metodologia de Avaliação Docente } \\
\hline & Aprovados & Reprovados & Matriculados & Valor P \\
Sem testes semanais & 67 & 94 & 161 & 0,0613 \\
Com testes semanais & 76 & 75 & 151 & 0 \\
\hline
\end{tabular}

Fonte: Adaptado de Zarpelon (2016)

Em relação à metodologia de avaliação diferenciada (dados na tabela 5), o teste sobre duas proporções não acusa uma melhora no desempenho em Cálculo I quando compara-se alunos submetidos a esta metodologia de avaliação com alunos submetidos a outras formas de avaliação (valor P > 0,05 o que sugere a igualdade entre as duas proporções amostrais). Ou seja, a metodologia de avaliações semanais na disciplina de Cálculo I parece não ter surtido o efeito esperado.

Cabe esclarecer que para esta variável foram comparados os desempenhos de quatro turmas do curso de Engenharia Eletrônica (duas delas participantes desta metodologia com avaliações semanais) e seis turmas de Engenharia de Produção (três delas participantes desta metodologia).

Ao aplicar-se os testes sobre duas proporções para o curso de Engenharia Eletrônica o resultado obtido (Valor $\mathrm{P}=0,6426$ ) indica que não há evidência suficiente para garantir que as proporções de aprovados em Cálculo I sejam diferentes para alunos submetidos à metodologias de avaliação distintas.

Por outro lado, quando aplica-se o teste para o curso de Engenharia de Produção os dados amostrais apoiam a afirmativa de que a proporção de 
alunos aprovados na disciplina de Cálculo I no período anterior à adoção dos testes semanais para fins de avaliação é menor do que a proporção de aprovados em Cálculo I após a adoção dos testes (Valor P=0,0079).

Uma possível explicação para esta diferença pode estar associada ao grau de comprometimento do aluno para estudar nos períodos extraclasse. Acadêmicos que almejassem um bom rendimento nos testes semanais deveriam estudar constantemente, buscando o entendimento contínuo dos conteúdos tratados na disciplina, não postergando as dúvidas e procurando saná-las conforme surgissem. Entretanto, esclarece-se que os acadêmicos de Engenharia Eletrônica possuem 5 aulas a mais que os estudantes de Engenharia de Produção, fato que pode impossibilitar uma dedicação maior por parte dos estudantes do primeiro curso e justificar a ineficácia dos testes no curso de Engenharia Eletrônica.

A estratégia adotada pelo docente responsável pela aplicação dos testes semanais vai ao encontro de uma proposta sugerida por Garzella (2013). Segundo a pesquisadora "a inclusão de um sistema de avaliação contínuo que possibilitasse ao professor uma constante reorganização das estratégias pedagógicas" (2013, p. 111) poderia alterar as condições presentes neste contexto de reprovações em Cálculo, desde que implicasse na revisão do rígido calendário utilizado, adaptando o mesmo às necessidades identificadas nas turmas.

Segundo o relato do professor responsável pela aplicação dos testes na UTFPR, após a adoção desta metodologia de avaliação muitos acadêmicos passaram o procurá-lo de forma mais intensiva nos horários de atendimento. Estes acadêmicos foram orientados a desenvolver atividades e resolver 
exercícios em grupo a fim de que pudessem discutir o conteúdo da disciplina. Segundo a percepção do professor, com o decorrer do tempo estes estudantes passaram a participar de forma mais ativa das atividades propostas nestes horários de atendimento e desenvolveram o hábito do estudo, o que representa um grande avanço no percurso acadêmico.

Quanto ao teste $\chi^{2}$ para independência, este sugere a existência de associação entre o desempenho em Cálculo I e as seguintes variáveis: nota obtida na prova de matemática do ENEM, pesos atribuídos às provas de Matemática do ENEM, período de ingresso no curso, carga horária semanal de aulas e conhecimento matemático prévio, conforme verifica-se no no quadro 3.

Quadro 3 - Conclusões obtidas no teste $\chi^{2}$ de independência

\begin{tabular}{|l|c|l|}
\hline \multicolumn{1}{|c|}{ Variável } & $\chi^{2}$ & \multicolumn{1}{c|}{ Conclusão } \\
\hline $\begin{array}{l}\text { Nota obtida na prova de } \\
\text { Matemática do ENEM }\end{array}$ & 102,652 & $\begin{array}{l}\text { Parece haver uma associação entre as variáveis } \\
\text { desempenho em Cálculo I e nota obtida na prova de } \\
\text { Matemática do ENEM. }\end{array}$ \\
\hline $\begin{array}{l}\text { Pesos adotados para as } \\
\text { provas de Matemática do } \\
\text { ENEM }\end{array}$ & 4,380 & $\begin{array}{l}\text { Parece haver uma associação entre as variáveis } \\
\text { desempenho em Cálculo I e peso atribuído para a } \\
\text { prova de Matemática do ENEM. }\end{array}$ \\
\hline $\begin{array}{l}\text { Período de ingresso no } \\
\text { curso }\end{array}$ & 68,842 & $\begin{array}{l}\text { Parece haver uma associação entre as variáveis } \\
\text { desempenho em Cálculo I e período de ingresso no } \\
\text { curso. }\end{array}$ \\
\hline $\begin{array}{l}\text { Conhecimento matemático } \\
\text { básico }\end{array}$ & 14,638 & $\begin{array}{l}\text { Parece existir uma associação entre as variáveis } \\
\text { desempenho em Cálculo I e conhecimento } \\
\text { matemático prévio. }\end{array}$ \\
\hline $\begin{array}{l}\text { Carga horária semanal de } \\
\text { aulas }\end{array}$ & 31,176 & $\begin{array}{l}\text { O resultado sugere haver uma associação entre as } \\
\text { variáveis desempenho em Cálculo I e carga horária } \\
\text { semanal de aulas. }\end{array}$ \\
\hline $\begin{array}{l}\text { Metodologia de avaliação } \\
\text { diferenciada }\end{array}$ & 2,384 & $\begin{array}{l}\text { Parece que o desempenho em Cálculo I independe } \\
\text { do desempenho do aluno nos testes semanais de } \\
\text { conhecimento. Ou seja, essas variáveis são } \\
\text { independentes. }\end{array}$ \\
\hline
\end{tabular}

Fonte: Adaptado de Zarpelon (2016) 
Note que apenas em relação à metodologia de avaliação diferenciada analisada neste estudo a dependência entre as variáveis é descartada (visto que o valor obtido para a estatística de teste $\chi^{2}=2,384<3,841$ ).

Assim, os resultados obtidos na aplicação do teste $\chi^{2}$ para independência apenas corroboram os resultados do teste sobre duas proporções.

\section{CONSIDERAÇÕES FINAIS}

Esta pesquisa teve como objetivo avaliar variáveis a fim de verificar quais delas são efetivamente significativas para a reprovação de alunos ingressantes de cursos de engenharia na disciplina de Cálculo Diferencial e Integral I. As variáveis investigadas estão associadas a dois eixos temáticos principais: conhecimento matemático prévio e estrutura didático/pedagógica dos cursos de engenharia.

Em relação ao primeiro eixo temático partiu-se da premissa que quatro variáveis poderiam influenciar no desempenho acadêmico em Cálculo I: nota obtida na prova de Matemática do ENEM, pesos adotados para a prova de Matemática do ENEM, período de ingresso no curso e conhecimento matemático básico.

Quanto ao segundo eixo temático, supôs-se que a carga horária de aulas a que os alunos ingressantes estão submetidos e o sistema de avaliação adotado poderiam interferir de alguma forma no desempenho em Cálculo I.

As conclusões obtidas a partir das análises acerca da nota obtida na prova de Matemática do ENEM, dos pesos adotados para essas provas e do desempenho alcançado no teste diagnóstico confirmam que o conhecimento 
prévio dos alunos ingressantes em relação à matemática básica é uma variável interveniente, conforme apontavam Cavasotto (2010), Lopes (1999), Menestrina e Moraes (2011), Santarosa e Moreira (2011), Soares de Mello e Fernandes (2001), e sugerem que alunos com maior aptidão matemática tendem a ter um desempenho melhor na disciplina de Cálculo I.

Além disso, o número de aprovações de alunos ingressantes em Cálculo I no primeiro semestre letivo é superior ao número de aprovações dos ingressantes no segundo semestre, fato que parece estar diretamente associado à nota obtida pelo aluno na prova do ENEM, o que em certa instância também reflete o nível de conhecimento do ingressante em matemática.

Ademais, verificou-se que a variável "metodologia de avaliação diferenciada" parece não afetar o rendimento do aluno na disciplina quando considera-se de forma única o universo pesquisado (alunos de Engenharia Eletrônica e alunos de Engenharia de Produção). Porém, ao analisar-se os cursos separadamente existem indicativos de que esta metodologia de avaliação semanal contribuiu para a melhora dos índices de aprovação no curso de Engenharia de Produção, possivelmente pelo fato dos alunos deste curso estarem submetidos a menores cargas horárias, o que possibilitou maior dedicação para o estudo extraclasse. Esta conclusão sugere que a carga horária de aulas dos alunos ingressantes pode ser um fator que influencie no desempenho acadêmico, o que reforça a necessidade de que a estrutura didática e pedagógica dos cursos de engenharia seja repensada.

Enfim, as variáveis apontadas neste estudo mostraram-se relacionadas, em alguma medida, aos índices de insucesso na disciplina de Cálculo I. Além disso, estas variáveis concorrem entre si, uma potencializando outra; fato que 
justifica a ineficácia das medidas paliativas pontuais adotadas por inúmeras instituições, como a oferta de disciplinas de Pré-Cálculo, monitorias, horários de atendimento extraclasse com os docentes da disciplina, entre outras.

Acredita-se que as estratégias adotadas para minimizar os índices de reprovação em Cálculo I devem ser pensadas e tomadas considerando várias frentes, e não serem iniciativas isoladas. Neste sentido é necessário um engajamento efetivo de todos os envolvidos no processo educativo: instituição, professores e alunos.

\section{REFERÊNCIAS}

BARBOSA, M. A. O insucesso no Ensino Aprendizagem na Disciplina de Cálculo Diferencial e Integral. 2004. 101f. Dissertação (Mestrado em Educação) Pontíficia Universidade Católica do Paraná, Curitiba, 2004.

BAZZO, W. A.; VALE PEREIRA, L. T. Introdução à engenharia: conceitos, ferramentas e comportamentos. 4. ed. Florianópolis, SC: Ed. da UFSC, 2013.

BOGAARD, M. Explaining student success in engineering education at Delft University of Technology: a literature synthesis. European Journal of Engineering Education, v.37, n.1, p. 59-82, mar., 2012.

CAVASOTTO, M. Dificuldades na aprendizagem de Cálculo: o que os erros podem informar. 2010. $141 \mathrm{f}$. Dissertação (Mestrado em Educação em Ciências e Matemática) - Pontifícia Universidade Católica do Rio Grande do Sul, Porto Alegre, 2010.

CRESWELL, J. W. Projeto de pesquisa: métodos qualitativo, quantitativo e misto. 3. ed. Porto Alegre, RS: Artmed, 2010.

CURI, R. C.; FARIAS, R. M. S. Métodos de estudo e sua influência no desempenho dos alunos em disciplinas de cálculo diferencial e integral. In: CONGRESSO BRASILEIRO DE ENSINO DE ENGENHARIA, 36, 2008, São Paulo. Anais... São Paulo, 2008. 
FERNANDES FILHO, O. P. O desenvolvimento cognitivo e a reprovação no curso de Engenharia. In: CONGRESSO BRASILEIRO DE ENSINO DE ENGENHARIA, 29. Anais... Porto Alegre, 2001.

GARZELLA, F. A. C. A disciplina de Cálculo I: a análise das relações entre as práticas pedagógicas do professor e seus impactos nos alunos. 2013. 298f. Tese (Doutorado em Educação) - Universidade Estadual de Campinas, São Paulo. 2013.

GIL, A. C. Como elaborar projetos de pesquisa. 4. ed. São Paulo, SP: Atlas, 2002.

HENSEL, R.; SIGLER, J. R.; LOWERY, A. Breaking the cycle of Calculus Failure: Models of Early Math Intervention to Enhance Engineering Retention. Disponível em: $<$ https://www.asee.org/public/conferences/8/papers/3737/download $>$. Acesso em 03 de novembro de 2015.

LOPES, A. Algumas reflexões sobre a questão do alto índice de reprovação no curso de Cálculo da UFRGS. Matemática Universitária. n.26/27, 1999.

LOPEZ, I. F.; SEGADAS, C. A disciplina de Cálculo I nos cursos de engenharia da UFRJ: sua relação com o acesso à universidade e sua importância para a conclusão do curso. REUCP, Petrópolis, v.8, n.2, p.92-107, 2014.

MENESTRINA, T. C., MORAES, A. F. Alternativas para uma aprendizagem Significativa em Engenharia: Curso de Matemática Básica. Revista Brasileira de Ensino de Engenharia, v.30, n.1, p.52-60, 2011.

SANTAROSA, M. C. P.; MOREIRA, M. A. O Cálculo nas aulas de Física da UFRGS: um estudo exploratório. Investigações em Ensino de Ciências, v. 16, n.2, p. 317-351, 2011.

SOARES DE MELLO, J. C. C. B.; SOARES DE MELLO M. H. C.; FERNANDES, A. J. S. Mudanças no ensino de Cálculo I: Histórico e Perspectivas. In: CONGRESSO BRASILEIRO DE ENSINO DE ENGENHARIA, 29. Anais... Porto Alegre, 2001.

TRIOLA, M. F. Introdução à estatística: atualização da tecnologia. 11. ed. Rio de Janeiro, RJ: LTC, 2014.

WITTE, R. S.; WITTE, J. S. Estatística. Rio de Janeiro, RJ: LTC, 2005. 
335 Análise do desempenho de alunos ingressantes de engenharia na disciplina de cálculo...

ZARPELON, E. Análise do desempenho de alunos de engenharia na disciplina de Cálculo Diferencial e Integral I: um estudo de caso na UTFPR. 2016. 117f. Dissertação (Mestrado em Ensino de Ciência e Tecnologia) - Universidade Tecnológica Federal do Paraná, Ponta Grossa, 2016.

Recebido: 04 de janeiro de 2017

Aceito: 02 de maio de 2017

Publicado: 10 de maio de 2017 